\title{
Regulation of Murine Dendritic Cell Functions by Calcium Channels
}

\author{
Gabriela Mellado-Sánchez, Héctor Vivanco-Cid, and Adriana Sumoza-Toledo* \\ Multidisciplinary Laboratory of Biomedical Sciences, Institute of Medico-Biological, Research Campus \\ Veracruz Universidad Veracruzana, Iturbide S/N. CP. 91700, Veracruz, Mexico
}

Received: July 14, 2014; Accepted: September 13, 2014; Published: September 28, 2014

*Corresponding author: Adriana Sumoza-Toledo, Multidisciplinary Laboratory of Biomedical Sciences, Institute of Medico-Biological, Research Campus Veracruz Universidad Veracruzana, Iturbide S/N. CP. 91700, Veracruz, Mexico, Tel: 2299318011; E-mail: asumoza@uv.mx

\begin{abstract}
Dendritic Cells (DCs) are highly potent Antigen-Presenting Cells (APCs) that have a key role in mediating tolerance or immunity to self and non-self antigens. In their immature stage DCs are highly phagocytic and undergo a maturation process after taking up an antigen. DC maturation is characterized by activation of mechanisms of antigen presentation, increased expression of Major Histocompatibility Complex (MHC) class II and co-stimulatory molecules in the plasma membrane, and secretion of cytokines and chemokines. Despite the fact that the role of calcium $\left(\mathrm{Ca}^{2+}\right)$ in DC function has been clearly established, regulation of $\mathrm{Ca}^{2+}$ signals in these cells is not well known. However, recently it has been demonstrated that functional capacitative $\mathrm{Ca}^{2+}$ release-activated $\mathrm{Ca}^{2+}$ (CRAC), Transient Receptor Potential Melastatin-2(TRPM2) and TRP Vanilloid- 1 (TRPV1) channels are critical for mouse DC maturation and migration. Also, Ryanodine Receptor-1 (RyR1) signaling activated by L-type $\mathrm{Ca}^{2+}$ channel CaV1.2 cause rapid MHC-II expression in the plasma membrane of DCs. The understanding of the regulation of $\mathrm{Ca}^{2+}$ signals in DCs is essential, to potentially modulate DC functions in disease processes. Therefore, in this review, we discuss recent studies on the expression and roles of $\mathrm{Ca}^{2+}$ channels in DC biology and function.
\end{abstract}

Keywords: Calcium; Dendritic cells; Ion channels; CRAC; TRPM2; TRPV1; RyR

\section{Introduction}

Dendritic cells (DCs) are Antigen-Presenting Cells (APCs) that play a critical role in the regulation of both: innate and adaptive immune responses. Initially, DCs were described by Ralph Steinman in 1973 [1], as a different immune cell population in the spleen and lymph nodes of mice. DCs are the only APCs that have the ability to induce a primary immune response in naïve $\mathrm{T}$ lymphocytes, and therefore they are considered the most potent APCs, influencing the type and quality of the response [2]. DCs can exist in two main states: In a steady state immature Dendritic Cells (iDCs) and fully mature DCs (mDCs). The distinction between immature and mature DCs is based on phenotypic markers and biological functions [3]. iDCs lack or have low levels of several important accessory molecules that mediate binding and stimulation of T cells, such as CD40, CD54, CD58, CD80, CD83 and CD86. They also express high levels of intracellular Major
Histocompatibility Complex (MHC) class II molecules. On the cell surface, iDCs express high levels of chemokine receptors such as CCR1, CCR5, and CCR6. Functionally, iDCs are characterized by high endocytic activity and low T-cell stimulation potential [47]. Phenotypic maturation is characterized by down-regulation of the capacity to capture antigens and up regulation of antigen processing and presentation functions. The mDCs phenotype is characterized by expression of high levels on the surface of MHC II, CCR7, CD40, CD54, CD80, CD83, CD86, CD58 and low expression of CCR1, CCR5, CCR6 [4-7]. DCs are also able to interact with other cells besides T cells, such as Natural Killer (NK) cells, neutrophils, and epithelial cells [8-10]. Other critical roles of DCs in immunity are the maintenance of B cell function, the establishment of immunological memory, and the maintenance of peripheral tolerance [11].

\section{Subsets}

DCs are widely distributed in all tissues, especially in those that provide an environmental interface, such as the skin and mucosal tissues. Similar to other immune cells, DCs are divided in subsets, which have been shown to possess a differential ontogeny, morphology, phenotype, transcriptional programs and functions [12]. In mice, DCs can be subdivided into CD8 ${ }^{+}$

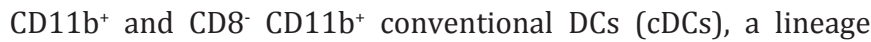
originated from a myeloid progenitor in the bone marrow. cDCs characteristically express high levels of MHC class II and the integrin CD11c, but not B220 marker [13-16]. cDC subsets are activated by microbial products through cell surface Toll- like Receptors (TLRs) to produce inflammatory cytokines such as interleukin (IL)-1, IL-6, IL-12, and tumor necrosis factor-alpha (TNF- $\alpha$ ) and they are specialized in the activation of $\mathrm{CD}^{+}$and $\mathrm{CD}^{+} \mathrm{T}$ cells [17]. They have a predominant role in MHC- II presentation and immunological tolerance, inducing clonal deletion of auto reactive $\mathrm{T}$ cell or Treg differentiation $[18,19]$. $\mathrm{CD}^{+} \mathrm{CD}^{-11 \mathrm{~b}^{+}} \mathrm{DCs}$ are specialized in the induction of $\mathrm{CD}^{+} \mathrm{T}$ cell immunity. They are the main source of IL-12 and IL- 15 [18], two cytokines involved in the differentiation of cytotoxic CD8 ${ }^{+} \mathrm{T}$ cells and have the ability to prime $\mathrm{CD}^{+} \mathrm{T}$ cell responses in a crosspresentation dependent mechanism [20]. CD8- CD11 b ${ }^{+}$cDCs can sense pathogens and migrate from non-lymphoid tissues to regional lymph nodes charged with self and foreign antigens. 
Other cDCs subsets include migratory $\mathrm{CD} 103^{+} \mathrm{CD} 11 \mathrm{~b}^{-} \mathrm{DCs}$, CD103- CD11 $^{+}$DCs, and Langerhans Cells (LCs), which are abundant in the intestinal mucosa and skin [21-24]. DCs can also be originated from a lymphoid progenitor. Plasmacytoid DCs (pDCs) are the prominent subset of this group, which phenotypically express CD8 $\alpha^{+}$CD $11 b^{-}$B $220^{+}$DC SING $[25,26]$. The other pDCs specific surface marker is the murine Siglec $\mathrm{H}$ [27]. pDCs are a specialized population that have the ability to produce very large amounts of interferon alpha/beta (IFN$\alpha / \beta)$ upon activation and a limited ability to prime naïve CD $4^{+}$ and CD8 ${ }^{+} \mathrm{T}$ cells. They are an important DCs subset in viral and anti-tumoral immunity [26]. Other DCs subsets include in vitro or in vivo inflammatory or infection-derived DCs, which develop from monocytes in response to stimulation such as GranulocyteMacrophage Colony-Stimulating Factor (GM-CSF), IL-4 and TNF- $\alpha$ [28]. A summary of DC subsets is showed in Table 1.

Early studies using $\mathrm{Ca}^{2+}$ ionophores and $\mathrm{Ca}^{+}$chelators have shown that $\mathrm{Ca}^{2+}$ signals may trigger maturation and functional properties of DCs [29-31]. Intracellular $\mathrm{Ca}^{2+}$ ions are crucial second messengers to initiate signaling pathways for fundamental cellular functions, such as cell cycle, survival, apoptosis, migration, and gene expression[32,33]. Regulation of intracellular $\mathrm{Ca}^{2+}$ concentrations $\left(\left[\mathrm{Ca}^{2+}\right]_{\mathrm{i}} ; \sim 100 \mathrm{nM}\right)$ involves both $\mathrm{Ca}^{2+}$ entry from the extracellular space and $\mathrm{Ca}^{2+}$ release from intracellular stores, such as calciosomes, Endoplasmic Reticulum (ER), lysosomes, or mitochondria, by specialized pumps and ion channels [32-34]. Although $\left[\mathrm{Ca}^{2+}\right]_{\mathrm{i}}$ increase triggers signaling pathways in the cell, the exquisite spatial and temporal organization of $\mathrm{Ca}^{2+}$ oscillations, waves and sparks might also provide a code for selective activation of signaling pathways and their duration. For example, a short $\left[\mathrm{Ca}^{2+}\right]_{\mathrm{i}}$ increase is observed in lymphocytes during immunological synapse, release of lytic granules, and cytotoxicity. In contrast, prolonged $\left[\mathrm{Ca}^{2+}\right]_{\mathrm{i}}$ increase regulates cytokine production, cell differentiation, effector

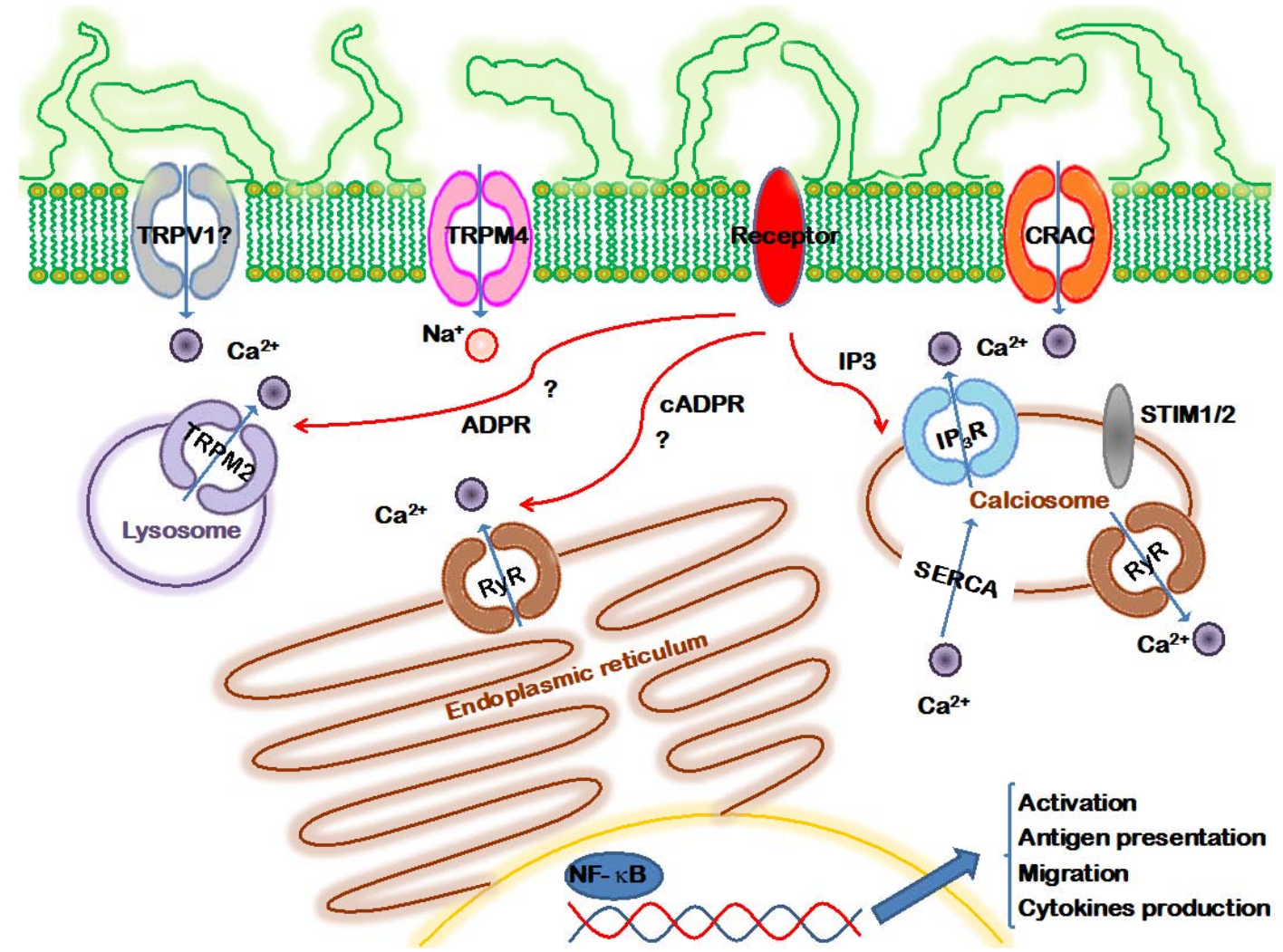

Figure 1: Calcium channels in DCs: Extracellular signals (chemokines, cytokines, microbial peptides, etc) are recognized by DCs by means of G protein-coupled receptors or receptor protein tyrosine kinases, activating the formation of 1,4,5-triphosphate (IP3) that in turn binds to IP3 receptors in the ER and calciosomes, causing $\mathrm{Ca}^{2+}$ release. Decrease in the luminal $\mathrm{Ca}^{2+}$ in the ER is detected by the Stromal Interaction Molecule 1/2 (STIM1/2) resulting in the activation of Capacitative $\mathrm{Ca}^{2+}$ Release-Activated $\mathrm{Ca}^{2+}$ (CRAC) channels, allowing $\mathrm{Ca}^{2+}$ influx across the plasma membrane. Chemokines also activate Transient Receptor Potential Melastatin- 2(TRPM2) channels in DC lysosomes. The $\mathrm{Ca}^{2+}$ signals activate transcription factors such as

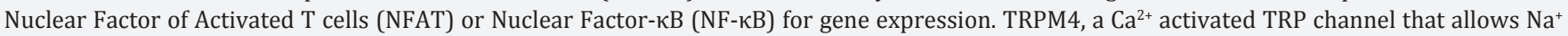
into the cell is expressed in the plasma membrane of DCs and indirectly regulates DC functions by decreasing the driving force for Ca ${ }^{2+}$ entry through CRAC channels. DCs also express TRP Vanilloid-1 (TRPV1) and Ryanodine receptor (RyR) channels but their functions are still not clear. 
Table 1: Dendritic cell subsets.

\begin{tabular}{|c|c|c|c|c|c|c|c|c|c|}
\hline DC subsets & $\operatorname{CD} 8 \alpha$ & CD103 & CD205 & CD11b & $\begin{array}{l}\text { B220 or } \\
\text { CD45RA }\end{array}$ & DC-SING & $\begin{array}{l}\text { Langerin } \\
\text { (CD207) }\end{array}$ & MHC class II & CD11c \\
\hline pDCs & + & - & - & - & + & ++ & - & + & + \\
\hline $\mathrm{CD} 8 \alpha+\mathrm{DCs}$ & + & low & + & + & - & - & $+/-$ & ++ & +++ \\
\hline $\mathrm{CD} 8 \alpha-\mathrm{CD} 11 \mathrm{~b}+\mathrm{DCs}$ & - & $+/-$ & + & + & - & ND & - & ++ & +++ \\
\hline CD103+ DCs & - & + & ++ & - & - & - & + & ++ & ++ \\
\hline $\begin{array}{c}\text { Lung } \\
\text { Intestine }\end{array}$ & - & + & - & + & - & - & - & + & ++ \\
\hline Langerhans cells & - & - & ++ & + & - & - & ++ & ++ & ++ \\
\hline $\begin{array}{l}\text { Monocyte-derived } \\
\text { inflammatory DCs }\end{array}$ & - & - & - & + & - & + & - & ++ & ++ \\
\hline
\end{tabular}

functions, etc. The present review addresses the role of $\mathrm{Ca}^{2+}$ channels in DC functions [33,35].

\section{$\mathrm{Ca}^{2+}$ Release-Activated $\mathrm{Ca}^{2+}$ Channels (CRAC) in DC}

The main mechanism for $\mathrm{Ca}^{2+}$ entry in immune cells, including DCs, is the Store-Operated $\mathrm{Ca}^{2+}$ Entry (SOCE). SOCE is activated by $\mathrm{Ca}^{2+}$ release from the intracellular stores and involves the activation of Capacitative $\mathrm{Ca}^{2+}$ Release-Activated $\mathrm{Ca}^{2+}$ (CRAC) channels in the plasma membrane (Figure 1) [34,36,37]. SOCE-mediated $\mathrm{Ca}^{2+}$ influx provides ions not only for signaling purposes, but also for ER and calciosomes store refilling. SOCE activation can be initiated by stimulation of $G$ protein-coupled receptors or stimulation of receptor protein tyrosine kinases by external signals (cytokines, chemokines, bacterial peptides, etc), leading to activation of Phospholipase C (PLC) that in turn hydrolyzes phosphatidylinositol- 4,5- bisphosphate (PIP2) to release Inositol-1,4,5-triphosphate (IP3) and Diacylglycerol (DAG) $[33,34]$.The subsequent binding of IP3 to IP3 receptors in the ER and calciosomes causes a rapid and transient $\mathrm{Ca}^{2+}$ release, raising the $\left[\mathrm{Ca}^{2+}\right]_{\mathrm{i}}$ (Figure 1). On the other hand, the decrease in the luminal $\mathrm{Ca}^{2+}$ in the ER is detected by the stromal interaction molecule 1/2 (STIM1, STIM2; $\mathrm{Ca}^{2+}$ sensors; Figure 1), resulting in its conformational change (oligomerization and aggregation) and activation of CRAC channels [33,34]. CRAC channels, which pore is formed by CRACM/Orai 1-3 proteins, then allow influx of extracellular $\mathrm{Ca}^{2+}$ across the plasma membrane (Figure 1). CRAC are highly $\mathrm{Ca}^{2+}$-selective, low conductance channels with a characteristic inwardly rectifying current-voltage relationship $[33,34]$. Interestingly, Orai and STIM proteins may have different tissue distribution, selectivity and conductivity for $\mathrm{Ca}^{2+}$.

As a result of $\left[\mathrm{Ca}^{2+}\right]_{\mathrm{i}}$ increase several signaling pathways and transcription factors are activated, such as the calmodulincalcineurin pathway that activate the Nuclear Factor of Activated $\mathrm{T}$ cells (NFAT), the $\mathrm{Ca}^{2+}$ - dependent kinase-calmodulin (CaMK) pathway which activate the Cyclic-adenosine monophosphateResponsive Element Binding protein (CREB), and the nuclear factor B (NFkB) pathway. Moreover, the DAG formed from PIP2 hydrolysis can activate the Protein kinase $C$ pathway (PKC), and Ras-mitogen-activated protein kinase, which ultimately activate transcription factors such as Activating Protein-2 (AP-2) and NFKB $[33,34]$.
Although the presence of CRAC currents and its role in DC maturation have previously been demonstrated in mouse DCs [36], it has only recently been shown that Orai2 and STIM2 are most abundant in DCs [38]. Furthermore, recruitment of Orai2 and STIM2 towards the immunological synapse has been observed during antigen presentation of DC to T lymphocytes [38]. Likewise, studies using CRAC blockers have shown that this channel plays an important role in DC maturation, cytokine production (TNF- $\alpha$ and IL-6) and chemotaxis [37]. DC maturation can be triggered in vitro by increasing $\left[\mathrm{Ca}^{2+}\right]_{\mathrm{i}}$ by stimulating them with peptidoglycan (PGN), CpG DNA, microbial products like Lipopolysaccharide (LPS) [39,40], or ionophores [29-31]. It has also been suggested that LPS, PGN and CpG induced activation of PLC $\gamma 2$ [39], which in turn acts on PIP2 to produce IP3 that leads to $\mathrm{Ca}^{2+}$ release from intracellular stores; followed by CRAC channel activation (reviewed in [34]) causing the nuclear translocation of calcineurin-dependent NFAT factor and cytokine production, such as IL-2 [33,41]. On other hand, DC maturation with $\mathrm{Ca}^{2+}$ ionophoresis associated with $\mathrm{NF} \kappa \mathrm{B}$ activation, likely by activating Calcium/Calmodulin-dependent Kinase II (CaMKII), which inactivates NFkB-inhibiting molecule IkB similar to what has been shown in T cells [42].

In addition, DC chemotaxis depends on $\mathrm{Ca}^{2+}$ influx. DC chemotactic response to chemokines, including (C-X-C motif) ligand 12 (CXCL12) and (C-C motif) ligand 21 (CCL21), results in PLC activation, IP3 production, $\mathrm{Ca}^{2+}$ release from intracellular stores, and subsequent activation of CRAC channels and $\mathrm{Ca}^{2+}$ influx $[31,40,43,44]$.

\section{Transient Receptor Potential (TRP) Channel in DC}

Our previous study has shown that lysosomal $\mathrm{Ca}^{2+}$ release through TRP Melastatin-2 (TRPM2) channel, the second member of the TRP melastatin-related channel family, plays an important role in DC maturation and chemotaxis (Figure 1) [40]. TRPM2 channel is expressed in DC only in lysosomes [40]. This channel is synergically activated by Adenosine Diphosphate Ribose (ADPR) and $\mathrm{Ca}^{2+}$, and allows entry of sodium $\left(\mathrm{Na}^{+}\right), \mathrm{Ca}^{2+}$, potassium $\left(\mathrm{K}^{+}\right)$ and caesium $\left(\mathrm{Cs}^{+}\right)$into the cytosol. In addition to $\mathrm{Ca}^{2+}$, cyclic ADPR (cADPR), hydrogen peroxide $\left(\mathrm{H}_{2} \mathrm{O}_{2}\right)$ and Nicotinic acid Adenine Dinucleotide Phosphate (NAADP) may directly or indirectly facilitate TRPM2 gating by ADPR [45]. DCs may produce ADPR by 
means of CD38 activity, an ectoenzyme that use $\beta$-Nicotinamide Adenine Dinucleotide $\left(\beta-\mathrm{NAD}^{+}\right)$as a substrate to catalyse the production of ADPR, CADPR, and NAADP, and by activation of the Poly(ADPR)-Polymerase/Poly(ADP-ribose) Glycohydrolase (PARP/PARG) pathway during DNA repair, replication and transcription [45]. DCs lacking TRPM2 channels express reduced levels of co stimulatory molecules, such as CD80, CD86, MHC-II and CD83, in the plasma membrane when they are stimulated with TNF- $\alpha$ and CpG DNA, than TRPM2 expressing-DCs [40]. They also show reduced $\mathrm{Ca}^{2+}$ signals in response to CXCL12 and CCL21, affecting the chemotaxis response towards these chemokines [40]. However, the mechanisms that link CD38 and PARP/PARG pathways to TRPM2 and to chemokine receptors are still not clearly understood.

DCs also express TRP Vanilloid-1 (TRPV1) protein in their plasma membrane, another non-selective $\mathrm{Ca}^{2+}$ channel of the TRP family, which is activated by capsaicin. But, there is controversial data on the expression and function of this channel in DCs. Earlier studies from Basu and Srivastava showed that extracellular $\mathrm{Ca}^{2+}$ influx via TRPV1 activation induces mouse DC maturation and provokes increase in the expression level of MHC class II and CD86 on the surface [46]. Conversely, O'Connell PJ et al. [47] did not detect TRPV1 transcripts and TRPV1 currents in bone marrow derived-mouse DCs. A recent study by Tóth BI et al. [48] shows molecular and functional expression of TRPV1 channels in monocyte derived-human DCs. Although DC stimulation with capsaicin induces $\mathrm{Ca}^{2+}$ mobilization, this reduces the expression level of maturation markers in DCs, such as CD83 and CCR7 [48]. On the other hand, TRPM4, a $\mathrm{Ca}^{2+}$-activated TRP channel that allows $\mathrm{Na}^{+}$into the cell, indirectly regulates $\mathrm{DC}$ migration but not maturation by decreasing the driving force for $\mathrm{Ca}^{2+}$ entry through CRAC channels [43].

\section{Ryanodine and Purinergic Receptors in DC}

Ryanodine Receptor-1 (RyR1), a channel expressed in intracellular $\mathrm{Ca}^{2+}$ stores, is also expressed in DCs $[49,50]$. RyR1 signaling coupled with L-type $\mathrm{Ca}^{2+}$ channel CaV1.2, which has been also detected in DCs, cause rapid MHC class II expression in the plasma membrane of DCs [50]. Interestingly, RyRs are also activated by cADPR and NAADP', and might contribute through these pathways to DC maturation $[44,51,52]$. Finally, DCs express Purinergic Receptors (P2Rs), P2X (ligand-gated ion channels) and P2Y (G-protein coupled receptors) on their surface, such as P2X1, P2X4, and P2X7, and P2Y1, P2Y2, P2Y4, P2Y6, P2Y11, and P2Y14, respectively. DC stimulation with Adenosine Triphosphate (ATP), a Damage-Associated Molecular Pattern (DAMP) molecule released by injured cells during inflammation and necrosis, or UTP results in characteristic $\mathrm{Ca}^{2+}$ signaling associated to P2X or P2Y, mainly P2X7 [53-57].

\section{Concluding Remarks}

Not much is known about $\mathrm{Ca}^{2+}$ channel expression and $\mathrm{Ca}^{2+}$ regulation in DCs. Recent studies have addressed the role of CRAC, TRPV1, TRPM2, RyR1 and CaV1.2 channels in DC maturation and migration. However, the mechanisms that lead to activation of these channels during DC function are not well understood. Moreover, future studies still need to address which channels regulate $\mathrm{Ca}^{2+}$ signals during antigen presentation, immune synapse, apoptosis, and other DC functions. The meaning of $\mathrm{Ca}^{2+}$ oscillations, frequency and patterns are unknown, which might play an important role in establishing and/or maintaining immunological tolerance or immunity to self and non-self antigens.

\section{References}

1. Steinman RM, Cohn ZA. Pillars Article: Identification of a novel cell type in peripheral lymphoid organs of mice. I. Morphology, quantitation, tissue distribution. J Immunol. 2007; 178(1): 5-25.

2. Guermonprez P, Valladeau J, Zitvogel L, Théry C, Amigorena S. Antigen presentation and $\mathrm{T}$ cell stimulation by dendritic cells. Annu Rev Immunol. 2002; 20: 621-67.

3. Merad M, Sathe P, Helft J, Miller J, Mortha A. The dendritic cell lineage: ontogeny and function of dendritic cells and their subsets in the steady state and the inflamed setting. Annu Rev Immunol. 2013; 31: 563-604. doi: 10.1146/annurev-immunol-020711-074950.

4. Dalod M, Chelbi R, Malissen B, Lawrence T. Dendritic cell maturation: functional specialization through signaling specificity and transcriptional programming. EMBO J. 2014; 33(10): 1104-1116. doi: 10.1002/embj.201488027.

5. Dieu MC, Vanbervliet B, Vicari A, Bridon JM, Oldham E, Aït-Yahia S, et al. Selective recruitment of immature and mature dendritic cells by distinct chemokines expressed in different anatomic sites. J Exp Med. 1998; 188(2): 373-386.

6. Sallusto F, Schaerli P, Loetscher P, Schaniel C, Lenig D, Mackay CR, et al. Rapid and coordinated switch in chemokine receptor expression during dendritic cell maturation. Eur J Immunol. 1998; 28(9): 2760 2769.

7. Yanagihara S, Komura E, Nagafune J, Watarai H, Yamaguchi Y. EBI1/ CCR7 is a new member of dendritic cell chemokine receptor that is up-regulated upon maturation. J Immunol. 1998; 161(6): 3096-3102.

8. Ferlazzo G, Morandi B. Cross-Talks between Natural Killer Cells and Distinct Subsets of Dendritic Cells. Front Immunol. 2014; 5: 159. doi: 10.3389/fimmu.2014.00159.

9. Bennouna S, Bliss SK, Curiel TJ, Denkers EY. Cross-talk in the innate immune system: neutrophils instruct recruitment and activation of dendritic cells during microbial infection. J Immunol. 2003; 171(11): 6052-6058.

10. Rescigno M. Dendritic cell-epithelial cell crosstalk in the gut. Immunol Rev. 2014; 260(1): 118-128. doi: 10.1111/imr.12181.

11. Liu YJ. Dendritic cell subsets and lineages, and their functions in innate and adaptive immunity. Cell. 2001; 106(3): 259-262.

12. Liu K. Nussenzweig MC. Origin and development of dendritic cells. Immunol Rev. 2010; 234(1): 45-54. doi: 10.1111/j.01052896.2009.00879.x

13. Vremec D, Zorbas M, Scollay R, Saunders DJ, Ardavin CF, Wu L, et al. The surface phenotype of dendritic cells purified from mouse thymus and spleen: investigation of the CD8 expression by a subpopulation of dendritic cells. J Exp Med. 1992; 176(1): 47-58.

14.Vremec D, Pooley J, Hochrein H, Wu L, Shortman K. CD4 and CD8 expression by dendritic cell subtypes in mouse thymus and spleen. J Immunol. 2000; 164(6): 2978-2986. 
15. den Haan JM, Lehar SM, Bevan MJ. CD8(+) but not CD8(-) dendritic cells cross-prime cytotoxic T cells in vivo. J Exp Med. 2000; 192(2): 1685-1696.

16. Belz GT, Nutt SL. Transcriptional programming of the dendritic cell network. Nat Rev Immunol. 2012; 12(2): 101-113. doi: 10.1038/ nri3149.

17. Kaisho T. Pathogen sensors and chemokine receptors in dendritic cell subsets. Vaccine. 2012; 30(52): 7652-7657. doi: 10.1016/j. vaccine.2012.10.043.

18. Maldonado RA, von Andrian UH. How tolerogenic dendritic cells induce regulatory T cells. Adv Immunol. 2010; 108: 111-165. doi: 10.1016/B978-0-12-380995-7.00004-5.

19. Steinman RM, Hawiger D, Nussenzweig MC. Tolerogenic dendritic cells. Annu Rev Immunol. 2003; 21: 685-711.

20. Morelli AE, Zahorchak AF, Larregina AT, Colvin BL, Logar AJ, Takayama T, et al. Cytokine production by mouse myeloid dendritic cells in relation to differentiation and terminal maturation induced by lipopolysaccharide or CD40 ligation. Blood. 2001; 98(5): 1512-1523.

21. Bedoui S, Whitney PG, Waithman J, Eidsmo L, Wakim L, Caminschi I, et al. Cross-presentation of viral and self antigens by skin-derived CD103+ dendritic cells. Nat Immunol. 2009; 10(5): 488-495. doi: 10.1038/ni.1724

22. Ng SC, Kamm MA, Stagg AJ, Knight SC. Intestinal dendritic cells: their role in bacterial recognition, lymphocyte homing, and intestinal inflammation. Inflamm Bowel Dis. 2010; 16(10): 1787-1807. doi: 10.1002/ibd.21247.

23. del Rio ML, Bernhardt G, Rodriguez-Barbosa JI, Förster R. Development and functional specialization of CD103+ dendritic cells. Immunol Rev. 2010; 234(1): 268-281. doi: 10.1111/j.0105-2896.2009.00874.x.

24. Milling S, Yrlid U, Cerovic V, MacPherson G. Subsets of migrating intestinal dendritic cells. Immunol Rev. 2010; 234(1): 259-267.

25. Asselin-Paturel C, Boonstra A, Dalod M, Durand I, Yessaad N, DezutterDambuyant $\mathrm{C}$, et al. Mouse type I IFN-producing cells are immature APCs with plasmacytoid morphology. Nat Immunol. 2001; 2(12): 1144-1150.

26. Reizis B, Bunin A, Ghosh HS, Lewis KL, Sisirak V. Plasmacytoid dendritic cells: recent progress and open questions. Annu Rev Immunol. 2011; 29: 163-183. doi: 10.1146/annurev-immunol-031210-101345.

27.Zhang J, Raper A, Sugita N, Hingorani R, Salio M, Palmowski MJ, et al. Characterization of Siglec- $\mathrm{H}$ as a novel endocytic receptor expressed on murine plasmacytoid dendritic cell precursors. Blood. 2006; 107(9): 3600-3608.

28. Segura E, Amigorena S. Inflammatory dendritic cells in mice and humans. Trends Immunol. 2013; 34(9): 440-445. doi: 10.1016/j. it.2013.06.001.

29. Bagley KC, Abdelwahab SF, Tuskan RG, Lewis GK. Calcium signaling through phospholipase $\mathrm{C}$ activates dendritic cells to mature and is necessary for the activation and maturation of dendritic cells induced by diverse agonists. Clin Diagn Lab Immunol. 2004; 11(1): 77-82.

30. Czerniecki BJ, Carter C, Rivoltini L, Koski GK, Kim HI, Weng DE, et al. Calcium ionophore-treated peripheral blood monocytes and dendritic cells rapidly display characteristics of activated dendritic cells. J Immunol. 1997; 159(8): 3823-3837.

31. Koski GK, Schwartz GN, Weng DE, Czerniecki BJ, Carter C, Gress RE, et al. Calcium mobilization in human myeloid cells results in acquisition of individual dendritic cell-like characteristics through discrete signaling pathways. J Immunol. 1999; 163(1): 82-92.

32. Chen YF, Chen YT, Chiu WT, Shen MR. Remodeling of calcium signaling in tumor progression. J Biomed Sci. 2013; 20: 23. doi: 10.1186/14230127-20-23.

33. Izquierdo JH, Bonilla-Abadía F, Cañas CA, Tobón GJ. Calcium, channels, intracellular signaling and autoimmunity. Reumatol Clin. 2014; 10(1): 43-47. doi: 10.1016/j.reuma.2013.05.008.

34. Shumilina E, Huber SM, Lang F. Ca2+ signaling in the regulation of dendritic cell functions. Am J Physiol Cell Physiol. 2011; 300(6): C1205-1214. doi: 10.1152/ajpcell.00039.2011.

35. Feske S. Calcium signalling in lymphocyte activation and disease. Nat Rev Immunol. 2007; 7(9): 690-702.

36. Hsu Sf, O'Connell PJ, Klyachko VA, Badminton MN, Thomson AW, Jackson MB, et al. Fundamental Ca2+ signaling mechanisms in mouse dendritic cells: CRAC is the major Ca2+ entry pathway. J Immunol. 2001; 166(10): 6126-6133.

37. Matzner N, Zemtsova IM, Nguyen TX, Duszenko M, Shumilina E, Lang F. Ion channels modulating mouse dendritic cell functions. J Immunol. 2008; 181(10): 6803-6809.

38. Bandyopadhyay BC, Pingle SC, Ahern GP. Store-operated $\mathrm{Ca}^{2}+$ signaling in dendritic cells occurs independently of STIM1. J Leukoc Biol. 2011; 89(1): 57-62. doi: 10.1189/jlb.0610381.

39. Aki D, Minoda Y, Yoshida H, Watanabe S, Yoshida R, Takaesu G, et al. Peptidoglycan and lipopolysaccharide activate PLCgamma2, leading to enhanced cytokine production in macrophages and dendritic cells. Genes Cells. 2008; 13(2): 199-208. doi: 10.1111/j.13652443.2007.01159.x.

40. Sumoza-Toledo A, Lange I, Cortado H, Bhagat H, Mori Y, Fleig A, et al. Dendritic cell maturation and chemotaxis is regulated by TRPM2mediated lysosomal Ca2+ release. FASEB J. 2011; 25(10): 3529-3542. doi: 10.1096/fj.10-178483.

41.Zanoni I , Ostuni R, Capuano G, Collini M, Caccia M, Ronchi AE, et al. CD14 regulates the dendritic cell life cycle after LPS exposure through NFAT activation. Nature. 2009; 460(7252): 264-268. doi: 10.1038/ nature08118.

42. Li Q, Verma IM. NF-kappaB regulation in the immune system. Nat Rev Immunol. 2002; 2(10): 725-734.

43. Barbet G, Demion M, Moura IC, Serafini N, Léger T, Vrtovsnik F, et al. The calcium-activated nonselective cation channel TRPM4 is essential for the migration but not the maturation of dendritic cells. Nat Immunol. 2008; 9(10): 1148-1156. doi: 10.1038/ni.1648.

44. Partida-Sanchez S, Gasser A, Fliegert R, Siebrands CC, Dammermann W, Shi G, et al. Chemotaxis of mouse bone marrow neutrophils and dendritic cells is controlled by adp-ribose, the major product generated by the CD38 enzyme reaction. J Immunol. 2007; 179(11): 7827-7839.

45. Sumoza-Toledo A, Penner R. TRPM2: a multifunctional ion channel for calcium signalling. J Physiol. 2011; 589(7): 1515-1525. doi: 10.1113/ jphysiol.2010.201855.

46. Basu S, Srivastava P. Immunological role of neuronal receptor vanilloid receptor 1 expressed on dendritic cells. Proc Natl Acad Sci U S A. 2005; 102(14): 5120-5125.

47. O'Connell PJ, Pingle SC, Ahern GP. Dendritic cells do not transduce inflammatory stimuli via the capsaicin receptor TRPV1. FEBS Lett. 2005; 579(23): 5135-5139. 
48. Tóth BI, Benko S, Szöllosi AG, Kovács L, Rajnavölgyi E, Bíró T. Transient receptor potential vanilloid-1 signaling inhibits differentiation and activation of human dendritic cells. FEBS Lett. 2009; 583(10): 16191624. doi: 10.1016/j.febslet.2009.04.031.

49. O'Connell PJ, Klyachko VA, Ahern GP. Identification of functional type 1 ryanodine receptors in mouse dendritic cells. FEBS Lett. 2002; 512(1-3): 67-70.

50.Vukcevic M, Spagnoli GC, Iezzi G, Zorzato F, Treves S. Ryanodine receptor activation by Ca $\mathrm{v} 1.2$ is involved in dendritic cell major histocompatibility complex class II surface expression. J Biol Chem. 2008(50); 283: 34913-34922. doi: 10.1074/jbc.M804472200.

51. Lee HC. Multiplicity of Ca2+ messengers and Ca2+ stores: a perspective from cyclic ADP-ribose and NAADP. Curr Mol Med. 2004; 4(3): 227 237.

52. Partida-Sánchez S, Goodrich S, Kusser K, Oppenheimer N, Randall TD, Lund FE. Regulation of dendritic cell trafficking by the ADP-ribosyl cyclase CD38: impact on the development of humoral immunity. Immunity. 2004; 20(3): 279-291.
53. Di Virgilio F. Purinergic mechanism in the immune system: A signal of danger for dendritic cells. Purinergic Signal. 2005; 1(3): 205-209. doi: 10.1007/s11302-005-6312-z.

54. Ferrari D, La Sala A, Chiozzi P, Morelli A, Falzoni S, Girolomoni G, et al. The P2 purinergic receptors of human dendritic cells: identification and coupling to cytokine release. FASEB J. 2000; 14(15): 2466-2476.

55. Mutini C, Falzoni S, Ferrari D, Chiozzi P, Morelli A, Baricordi OR, et al. Mouse dendritic cells express the P2X7 purinergic receptor: characterization and possible participation in antigen presentation. J Immunol. 1999; 163(4): 1958-1965.

56. Schnurr M, Toy T, Stoitzner P, Cameron P, Shin A, Beecroft T, et al. ATP gradients inhibit the migratory capacity of specific human dendritic cell types: implications for P2Y11 receptor signaling. Blood. 2003; 102(2): 613-620.

57. Shin A, Toy T, Rothenfusser S, Robson N, Vorac J, Dauer M, et al. P2Y receptor signaling regulates phenotype and IFN-alpha secretion of human plasmacytoid dendritic cells. Blood. 2008; 111(6): 3062-3069. 